\title{
CRUCES GENÉRICOS Y DE MATERIAS NARRATIVAS. MOTIVOS TRADICIONALES EN LE ROMAN D'AUBERONY HUON DE BORDEAUX
}

\author{
Juan Manuel Lacalle \\ Universidad de Buenos Aires \\ jmlacalle@filo.uba.ar
}

\begin{abstract}
Resumen: El presente artículo se detendrá en el análisis de Le roman $d^{\prime}$ Auberon y, de manera satelital, en Huon de Bordeaux, textos que concluyen y dan inicio, respectivamente, al ciclo de Huon de Bordeaux. Nuestra hipótesis es que Auberon funciona narrativamente como el personaje conciliatorio por excelencia, ya que no solo colabora de forma determinante con la finalización del conflicto entre el señor y su vasallo en Huon de Bordeaux (Huon vuelve del exilio y se reconcilia con Carlomagno gracias, principalmente, a Auberon), sino que, además, confluyen en su figura diversas tradiciones medievales literariodiscursivas (que entran en juego genéricamente como cantar de gesta y roman) y culturales (relacionadas con las materias bretona, francesa y romana). En esta ocasión, nos focalizaremos sobre una de las herramientas formales a través de la que se plasma esta hibridez: la variedad de motivos.
\end{abstract}

Palabras clave: Huon de Bordeaux, Le roman d'Auberon, Motivos.

\begin{abstract}
This article focuses on the analysis of Le roman $d^{\prime}$ Auberon and, tangentially, in Huon de Bordeaux, texts that conclude and initiate, respectively, the cycle of Huon de Bordeaux. Our hypothesis is that Auberon functions narratively as the conciliatory character par excellence, as he collaborates decisively with the end of the conflict between the lord and his vassal in Huon de Bordeaux (Huon returns from exile and reconciles with Charlemagne thanks, mainly, to Auberon). In addition, different literary-discursive (which come into play generically as chanson de geste and roman) and cultural medieval traditions (related to Breton, French and Roman materias) come together in his figure. On this occasion, we will focus on one of the formal tools through which this hybridity takes shape: the variety of motifs.
\end{abstract}

Keywords: Huon de Bordeaux, Le roman d'Auberon, Motifs. 
Le roman d'Auberon funciona a modo de precuela del cantar de gesta Huon de Bordeaux (ca. 1260). Allí se narra la historia del linaje del rey hada y se cuentan las genealogías de ciertos objetos y personajes maravillosos. El texto se conserva en un único manuscrito fechado en 1311 y escrito en decasílabos rimados (Ms. L II 14 de la Biblioteca de Turín, ff. 283 r. - 296 v. A partir de allí, y hasta el folio 460, se encuentra el resto del ciclo de Huon de Bordeaux). El manuscrito se compone en su totalidad de 586 folios a dos columnas de 45 versos cada una. Específicamente, Auberon cuenta con un total de 2468 versos repartidos en 51 tiradas. Además, entre sus folios hay tres iluminaciones: la huida de Egipto (f. 291 r.), dos cazadores (f. 283 r.) y un grupo de guerreros (f. 289 r.). Por último, recordemos que el testimonio, mutilado tras el incendio de la Biblioteca de Turín en 1904, cuenta con usos picardos y, en menor medida, vocabulario tanto en valón como en lorenés. En relación con las tiradas, a diferencia de Huon, son mucho más breves y nunca se progresa paralelamente con dos acciones sino que, en cambio, el relato se desarrolla de manera lineal.

El texto cierra el ciclo iniciado por Huon de Bordeaux mediante la narración de los orígenes (ciclo compuesto, también, por Esclarmonde, Clarisse et Florent, Y de et Olive y Godin). Ciertas líneas argumentales de Huon se amplifican y, en consecuencia, se explicita cómo y por qué se llega a determinadas situaciones narradas. La confluencia genérica y genealógica de tradiciones que se observaba en Huon se 
extiende en el roman. Allí, se efectiviza teleológicamente la constitución de un personaje que cruza distintas tradiciones culturales y literarias. En este sentido es que afirmamos que Auberon es el personaje conciliatorio por excelencia, ya que no solo termina con el conflicto entre el señor y su vasallo en Huon de Bordeaux (Huon vuelve del exilio y se reconcilia con Carlomagno gracias, principalmente, a Auberon), sino que, además, confluyen en su figura diversas tradiciones literariodiscursivas (especialmente, el cantar de gesta y el roman) y culturales (relacionadas con las materias bretona, francesa y romana). Por añadidura, todo este conjunto es atravesado por un matiz de cristianización de lo maravilloso, más presente aún en Le roman d'Auberon que en Huon de Bordeaux.

En otro orden, recordemos que en el caso de Auberon no contamos con una traducción al español ni al francés moderno, sino que para el análisis del texto debemos atenernos a la edición más reciente, publicada en 1973 por Jean Subrenat. Allí, el editor señala dos grandes vertientes de fuentes: las "profanas" (el propio Huon de Bordeaux, el ciclo artúrico y la historia romana) y las religiosas (Judas Macabeo, la vida de San Jorge y la infancia de Cristo). El elemento más obvio que vincula al texto con las diferentes tradiciones es, en varios casos, la referencia onomástica, a través de los propios personajes que componen el árbol genealógico del hada-enano. Podríamos pensar en su totalidad a Le roman d'Auberon como

1 En esta línea, he trabajado particularmente con el énfasis en Huon de Bordeaux. Por un lado, a partir del análisis del tratamiento de los motivos maravillosos (Lacalle, 2014a) y, por otro lado, sobre la hibridez genérica y la recepción decimonónica del contrapunto roman-chanson de geste del texto (Lacalle, 2014b). 
un relato genealógico de la vida de Auberon y, en este sentido, como una amplificatio de la descripción del narrador en el prólogo de Huon de Bordeaux y de la propia presentación del personaje cuando Huon y sus compañeros lo encuentran en el bosque por primera vez.

La narración comienza con la vida de Judas Macabeo, bisabuelo de Auberon, descripto como hombre notable y servicial con Dios, "frans de cuer", "humles et pius" y calificado como "grans", "fors", "biaus", "gracieus" y "preus". En contraposición, el rey Brandifort, "orguilleus", es quien lo ataca por celos. La figura de Judas Macabeo encarna toda una vertiente guerrera vinculada con la épica. Así, el personaje de Judas permite el sincretismo de la épica con la Biblia (no obstante, las divergencias son numerosas entre la vida relatada en los dos Libros de los Macabeos y las particularidades que el autor de Auberon le otorga). Por lo tanto, los principales valores que se destacan de Judas Macabeo son la piedad religiosa y la capacidad guerrera. El bisabuelo de Auberon, entonces, se casa con la hija de su propio enemigo (aquí no podemos dejar de destacar el intertexto con la relación que se establece en Huon de Bordeaux entre Huon y Esclarmonde, hija del emir de Babilonia, Gaudisse, a quien Huon debe sustraerle cuatro muelas y su barba, entre otros elementos, para obtener el perdón de Carlomagno y retornar del exilio).

De la unión de Judas con la hija de Brandifort nace la abuela de Auberon, Brunehaut, con quien se introduce el elemento maravilloso. El paralelismo entre la vida de Auberon y su abuela, Brunehaut, (y, por extensión, el juego intertextual con Huon) es notable. Por ejemplo, ambos reciben dones similares 
de cuatro hadas. Como sucederá con su nieto, uno de los dones implica que a los siete años algo ocurrirá: en su caso, el hada le anticipa que a esa edad dejará a su familia para habitar en el reino de Faerie. Cumplidos los siete años, el hada que le había dado el don la va a buscar metamorfoseada en ciervo. Este mismo ser sobrenatural tiene dos hijos con Mantenor: Gloriant y Malabron, los dos vasallos maravillosos de Auberon que ayudan a Huon en sus periplos en Huon de Bordeaux. En cuanto a los cuatro dones de las hadas que recibe Auberon, en Le roman d'Auberon son más breves y precisos, además de ser tres en lugar de cuatro. No obstante, dan testimonio de la fuente principal del roman. Por un lado, en Huon se le otorga: 1) no crecer más luego de los tres años $y$, paralelamente, tener una belleza física sin parangón; 2) conocer el pensamiento y el corazón de los hombres; 3) poder trasladarse instantáneamente hacia donde desee; 4) tener control sobre los animales y conocer los secretos del Paraíso y los ángeles. Asimismo, tras su muerte, se le reservará un lugar al lado de Dios. Por otro lado, en Auberon los dones se resumen a: 1) lograr todo lo deseado y tener autoridad sobre la herencia de Julio César y los seres "faés"; 2) no crecer más de tres pies a los siete años (aquí probablemente haya habido una confusión o, por lo menos, un guiño a los tres años de Huon); 3) tener beldad extrema, una vida larga y el poder de dejar sus dones mágicos a quien desee. Los dones son similares, aunque en Auberon se encuentran más psicológicamente elaborados y se agrega el don de Morgana (como un hada más), quien le promete el Paraíso a su hijo. Por su parte, Subrenat señala que los dones se encuentran estructurados en Auberon más coherentemente; para 
ejemplificar, un hada le da el don negativo (ser enano giboso) y la otra trata de subsanarlo dándole extrema belleza (en Huon el mismo personaje realizaba las dos acciones).

Retomando la genealogía, Césaire pide la mano de Brunehaut y de su unión nace ni más ni menos que Julio César, quien será criado por Judas. Julio, además de traer a colación en los intertextos del lector toda la cultura romana es, también, emblema de la conquista y de la unificación imperial de culturas diversas. Por ello, en Huon de Bordeaux no deja de recalcarse que gobierna Hungría, Austria y Constantinopla. En Auberon, en cambio, se le adjudican Hungría, Austria, India, Monmur y Romania. Por añadidura, Julio César recibe de su madre la armadura maravillosa que aparecía en Huon y será uno de los principales intertextos narratológicos entre el primer y el último texto del ciclo. Le roman d'Auberon pareciera explicar la extraña razón por la cual Auberon ayuda a Huon continuamente en su aventura a pesar, incluso, de las numerosas desobediencias del héroe. Sobre el final del roman, en la anteúltima laisse, la número L, Brunehaut le predice a Auberon el nacimiento de Huon, quien será el encargado de vencer al gigante Orgulloso y recuperar la armadura maravillosa y el castillo de Dunostre (episodio que tiene lugar en Huon). Brunehaut le hace una predicción a su nieto:

Hauberon niés, dist la dame, entendés/ ne faites duel, ce seroit foletés/ soiés seürs que vo haubert rarés/ et Dunostre dont tant iestes irés/ car dou geant moult bien vengiés serés/ dedens Bordiaus est hui uns enfes nés/ fieux est Seuwyn qui tant est renomés/ Chambrelains est Chalemaingne, le ber/ Huelins est li enfes apelés (vv. 23708). 
Brunehaut le había obsequiado la armadura maravillosa a su hijo para luchar contra el gigante Brulant que devastaba Hungría. El texto cierra la última tirada haciendo hincapié en la venganza de Huon: 'Dusqu'a I. jour que vous dire m'orés/ que Huelins la vint de la geter/ cil de Bordelle qui tant fist a loer" (vv. 2466-8). Además de la armadura, hay otro elemento maravilloso presente en ambos relatos. En Auberon, el cuerno mágico es propiedad de Morgana, quien lo heredó de su padre. Allí se le da una sola virtud: que una gran cantidad de vasallos aparezcan armados. En cambio, en Huon se agregan otras habilidades: sanar con su sonido y hacer bailar, entre otras. La copa, fuente inagotable de vino en los dos textos, no delata a los pecadores al desaparecer en Auberon.

Todos estos elementos, si bien ya introducidos por Brunehaut, se multiplican con el casamiento entre Julio César y el hada Morgana, hermana del rey Arturo. De su matrimonio nacen dos hijos: Georges y Auberon. En contraposición, en Huon de Bordeaux el hada-enano es hijo único. Los padres continúan rigiendo en sus respectivos reinos: Julio César en Monmur (donde cría a Georges) y Morgana en Dunostre (se encarga de Auberon). Luego del casamiento de Georges, Auberon parte a Monmur en compañía de Gloriant y Malabron. Allí terminarán en un banquete en la corte del rey Arturo. Resulta curioso que el personaje del rey Arturo aparezca siempre mencionado, pero nunca en escena. Las presencias de Morgana y Arturo abren el interrogante sobre qué lugar ocupa Huon de Bordeaux en la leyenda artúrica (y viceversa). Dado que Arturo no aparece directamente, analizaremos especialmente la figura de Morgana. Se la adjetiva 
como "sage" y como buena madre, con preferencia por Auberon. El roman reescribe la historia de Morgana, borrando los intertextos negativos. Ella está casada legítimamente con Julio César, sin adulterio. El término que se utiliza es "servaige". El hada evoca la ciencia, la sabiduría y la dulzura. Asimismo, en ella se condensan el origen y las cualidades de los objetos mágicos. En relación con la construcción del personaje de Morgana, de acuerdo con dos vertientes históricas diferentes, Caroline Casanave señala:

Choisie d'un côté pour sa science, ses pouvoirs, sa beauté, d'un autre pour établir une junction entre la chanson de geste et le roman arthurien, au moment où la trame de Huon de Bordeaux est en phase de constitution poétique, Morgue n'apporte pas dans son sillage un modèle de perversité qu'un auteur pourrait feindre d'ignorer (Casanave, 2008, p. 33).

En Auberon confluyen finalmente las figuras de Julio César y Morgana, o genéricamente el roman antique y el roman arthurien; "[...] avec Auberon, des noces textuelles mettent au monde un nouveau type de formule littérarie" (Casanave, 2008, p. 4). Auberon es, también, sincretismo de paganismo y cristianismo. Esta síntesis implica una construcción en dirección moral y religiosa, cuya propia cualidad sintética le otorgaría mayor autoridad, por su amplitud abarcadora, ante un espectro más extenso de personajes y receptores. Esto se observa constantemente en ambos textos cuando se ponen en juego problemas éticos como la traición, el honor y la lealtad, y sus respectivas resoluciones, siempre de la mano de Auberon. 


\section{Motivos tradicionales}

El análisis de motivos provenientes de diversas tradiciones permite enfocar, mediante una herramienta formal y sobre un aspecto puntual, el trabajo conjunto en ambos textos. ${ }^{2}$ Los fenómenos de interfiguración e intermotivación conectan los textos entre sí interdiscursivamente y, a su vez, los hacen cohesivos consigo mismos, de manera intratextual; relaciones relevantes para los ciclos medievales, con la característica añadida en este caso de la cualidad de precuela de Auberon. La similitud de versos y el contraste entre los textos son elementos que podrían condicionar la recepción de lo que sigue en el relato. Para poder entender estos fenómenos, hay que enfocar la lectura desde la teoría de la recepción y, así, poder acceder a una comprensión más cercana a la propia de los receptores medievales. El motivo de hacer sonar el olifante, que aparece sobre el final de Huon, remitiría a una derrota. Por consiguiente, este aspecto que vincula a Huon con Roldán hace pensar en una derrota inminente $\mathrm{y}$, asimismo, realza la importancia de la ayuda de Auberon. No obstante, Norris Lacy (1996) señala que la duplicación de un motivo enfatiza la diferencia más que la similitud y genera una especie de "efecto palimpsesto" a través del cual el receptor se conecta con resonancias tematológicas previas y con motivos anteriores.

\footnotetext{
2 Resultan productivos para este análisis, en primer lugar, el Motif Index of Folk Literature de Stith Thompson y, más especialmente, el Index des motifs narratifs dans les romans arthuriens francais en vers (XIIe-XIIIe siècles) de Guerreau-Jalabert, y los capítulos relativos a la temática de motivos en Huon de Bordeaux et l'évolution du genre épique an XIIIe siècle de Marguerite Rossi.
} 
Inevitablemente, nuestro imaginario funciona también de manera prospectiva. Más aún, con textos vinculados cíclicamente como Le roman d'Auberon y Huon de Bordeaux. ${ }^{3}$

A continuación, en nuestra investigación relevamos los motivos presentes en los textos, de acuerdo con las clasificaciones de Stith Thompson (ST) y Guerreau-Jalabert (GJ), y los puntos de contacto con las obras artúricas de acuerdo con el tratamiento de esta última. ${ }^{4}$

3 Por consiguiente, la transferencia de motivos resulta de vital importancia para la cohesión en la confección de ciclos, más allá de los aspectos cronológicos: "[...] the recycling of motifs that, when assigned to another character, provide a cohesive effect while transforming and extending the meaning" (Lacy, 1996, p. 167).

${ }^{4}$ D-Magic. D 199.3 Transformación de hombre en bestia marina ST. D 806 Objeto mágico cuyas cualidades solo pueden darse tras seguir una serie de instrucciones ST. D 805 Objeto mágico que debe ser utilizado solo en caso de extrema necesidad ST. D 810 Objeto mágico como regalo ST y GJ (Continuación Perceval I y II, Continuación de Gerbert de Montreuil, Yonec, Coronación Mantle). D 812 Objeto mágico recibido de un ser sobrenatural ST y GJ. D 812.12 Objeto mágico recibido de un enano ST. D 813 Objetos mágicos recibidos de un hada ST y GJ (Continuación Perceval I, Continuación de Gerbert de Montreuil, Yvain, Lancelot, Tyolet, Desiré, Lai du cor, Coronación Mantle). D 833 Objeto mágico adquirido tras engañar a un gigante ST. D 838.6 Objeto mágico robado por un gigante. D 838.7 Armadura de un enano robada por un gigante ST. D 905 Provocar una tormenta mágicamente ST y GJ (Continuación Perceval I y II, Continuación Perceval de Menessier, Rigomer, Yvain). D 915 Río mágico ST. D 941 Bosque mágico ST y GJ (Claris). D 1046 Vino mágico ST. D 1076 Anillo mágico ST y GJ (Continuación Perceval I y II, Desiré, Lancelot, Melion, Rigomer, Venganza de Raguidel, Yonec, Yvain). D 1091-1092 Arco y flecha mágicos ST. D 1101 Armadura mágica ST y GJ (Continuación Perceval I y II, Continuación Perceval de Gerbert de Montreuil, Fergus, Venganza de Raguide). D 1131 Castillo encantado ST. D 1151 Asiento mágico (Continuación Perceval de Gerbert de Montreuil, Durmart). D 1170 Transformación de hombre a pez ST. D 1171.6 Cáliz mágico ST y GJ (Conte du Graal, Continuación Perceval I, II, de Gerbert de Montreuil y de Manessier). D 1222 Cuerno musical. ST y GJ (Continuación Perceval I, Rigomer). D 1299.3 Cruz mágica ST. D 1317.0.1 Objeto mágico que reconoce el veneno ST y GJ (Lancelot). D 1338.1.1 Fuente de la juventud ST. D 1359.3.1.1 Alivia las penas ST y GJ (Continuación Perceval de Gerbert de Montreuil, Escanor, Bel Inconnu). D 1381.10 Armadura mágica protectora de los ataques ST. D 1415.2.1 Causa la danza ST. D 1421.5.1 Convoca un ejército para el rescate ST. D 1440.1 Controla a los animales ST y GJ (Continuación Perceval II). D 1472.1.14.1 Copa que provee bebida ST y GJ (Continuación Perceval I, Manessier y Gerbert de Montreni). D 1620 Autómatas mágicos ST y GJ (Continuación Perceval I, Escanor, Rigomer). D 1766.6 La magia 
Cada uno de los motivos puede rastrearse en los relatos anónimos Huon de Bordeaux y Le roman d'Auberon. Para reforzar la importancia teórica de la herramienta de los motivos, recordemos los tres objetivos que plantea Guerreau-Jalabert en su introducción: 1) facilitar el acceso a los textos extensos; 2) permitir la comparación y la localización de temas narrativos en un corpus frondoso y repetitivo (en su caso dentro de lo artúrico, pero se podría ampliar el recurso hacia otras tradiciones narrativas); 3) establecer una relación temática ente los textos pertenecientes a la "materia artúrica" con el resto de las tradiciones. De esta manera, los motivos (más o menos generales o particulares) permitirían ligar textos y establecer relaciones. Por su parte, los índices posibilitan el acceso intertextual a secuencias narrativas $y$, temáticamente, habilitan el trabajo con la articulación del relato. En este sentido, Guerreau-Jalabert señala la importancia del análisis puntilloso y detallado del texto motivo-por-motivo:

resulta tras efectuar una cruz. ST y GJ (Autre Périlleux, Bel Inconnu, Continuación Perceval de Gerbert de Montrenily de Manessier).

F-Marvels. F 141.1 Río como barrera para entrar al otro mundo. ST y GJ (Graelent, Guingamor, Lanval, Tyolet). F 200 Hadas. ST y GJ (Bel inconnu, Claris, Continuación Perceval I, II, Gerbert de Montrenil y Manessier, Desiré, Erec, Escanor, Floriant, Guingamor, Lanval, Mantle, Rigomer, Raguide). F 210 Tierra de las hadas. ST y GJ (Floriant). F 216 Las hadas viven en un bosque. ST y GJ (Claris, Cotinuación Perceval II, Desiré, Guingamor, Rigomer). F 230 Aparición del hada. ST. F 234.1.4 Hada en forma de ciervo. ST. F 340 Regalos de hadas. ST y GJ (Continuación Perceval II, Gerbert de Montreuil, Lai du cor, Desiré, Erec, Floriant, Graelent, Lancelot, Lanval, Mantle, Rigolet, Tyolet, Yvain). F 451.5.1.6.1 Dones del enano cesan con la traición. ST. F 451.5.1. Helpful dwarfs. ST y GJ (Autre Périlleux, Bel inconnu, Merangis).

H-Tests. H 251.3.13 Copa mágica que sirve para probar la verdad o la falsedad. ST H 263 Pruebas de pecado. ST y GJ (Conte du Graal, Continuación Perceval II y de Gerbert de MontreniD. H 200-299 Pruebas de verdad. ST y GJ.

Otros motivos en Stith Thompson: $\mathbf{Z}$ 72.01 Tiempo límite de un año para la aventura. ST Z 254 Héroe destinado. W 158 Lugar inhóspito. V 20 Confesión de pecados. 21 Dar el perdón. V 294 El Papa da el perdón. V 316 Eficacia del rezo. V 331 Conversión al cristianismo. T 32.1 La amante rescata a su amado de la prisión de su propio padre. 
"Il est irréaliste d'imaginer qu'une adéquation exacte puisse être trouvée entre un motif et une séquence narrative, sauf à formuler un motif pour chaque séquence ou fraction de séquence" (Guerreau-Jalabert, 1992, p. 7).

En el extenso análisis de Marguerite Rossi sobre Huon contamos con el apartado "Les motifs dans Huon de Bordeaux". Allí, Rossi retoma y parafrasea la definición de "motivo" de Jean Rychner: "[...] fragments de récits ou récits brefs mais complets que les poètes épiques reçoivent tout constitués et ont ajustés les uns aux autres pour composer les diverses chansons de geste" (Rossi, 1975, p. 159). Es el caso, en general, de gran parte de la literatura medieval: se presenta como una renovación de temas y relatos ya conocidos. En principio, Rossi afirma que no es su intención realizar un análisis narrativo detallado sobre los motivos, dada la extensión del texto, y que la conclusión literaria a la que se arribaría no sería significativa, sino que se llegaría meramente a un inventario de motivos épicos (similar al que hemos desarrollado en nuestra cuarta nota). Asimismo, y si seguimos su razonamiento, "[...] tout élément narratif que nous rencontrons dans une épopée est motif: s'il est stéréotypé ou non, seule la comparaison pourrait permettre de le dire avec certitude" (Rossi, 1975, p. 160). No obstante, a continuación, se encarga de realizar una enumeración de los motivos épicos tradicionales trabajados por Rychner que se encuentran presentes en el texto. Allí menciona, también, la cantidad de

\footnotetext{
5 Subsumido en "La technique épique et son utilisation" del Capítulo IV de Huon de Bordeaux et l'évolution du genre épique au XIIIe siècle. Las otras tres partes del capítulo son: las fórmulas, las tiradas y la composición.
} 
veces que distingue cada motivo en su rastreo: l'armament (21), coup d'épée (18), repas (25), arrivée d'un messager ou d'un étranger à une cour royale (10), adieux (10). Además, menciona: essai du cheval, bataille, héros dans la mêlée, combat singulier décidant la sort de la guerre, prières, regrets sur le béros, pleurs, poursuites, songes, saluts.

Como primera conclusión de la proliferación de motivos épicos, y avalando su hipótesis, Rossi señala que Huon de Bordeaux sería la obra de un escritor familiarizado con el repertorio narrativo épico. ${ }^{6} \mathrm{Al}$ tratarse de un poema tardío, los motivos se habrían desarrollado de manera diversa. Por ejemplo, en relación con la clasificación de Rychner de la existencia de variantes breves y extensas para cada motivo en particular, Rossi distingue: “[...] ce que l'on observe le plus fréquemment dans Huon de Bordeaux est une tendence à réduire le plus possible les développements traditionnels" (Rossi, 1975, p. 162). Así, los motivos más corrientes de los cantares de gesta, a pesar de ser numerosos en Huon, se extienden durante solo uno o dos versos o, menos aún, un hemistiquio. Parafraseando a Rossi, podríamos decir que el autor se "contenta con una referencia alusiva". Sin embargo, hay que tener en cuenta que la alusión reenvía a cuestiones conocidas por los contemporáneos del texto. De esta manera, los motivos le dan cierto dinamismo al relato al reducir hasta el extremo los motivos más estereotipados. Por consiguiente, mediante motivos épicos breves se reenvía a una tradición previa, operación propia de los cantares tardíos. Por otra parte,

6 En la introducción, Rossi concluye: “[...] on le lira aussi comme une épopée authentique, bien différente du produit dégénéré de la contamination du genre épique par le roman qu'on a trop souvent voulu voir dans cette oeuvre" (Rossi, 1975, p. 18). 
estos motivos breves suelen estar seguidos de sucesos ligados a la aventura y a lo maravilloso. A modo de ejemplo, recordemos los banquetes en el bosque de Auberon y las escenas de separación y despedida (antes del viaje a Oriente). En contraposición, los motivos tradicionales aparecen más desarrollados cuando su tema reviste cierta importancia en la intriga del poema o cuando se vinculan con un episodio de acción. Adicionalmente, permiten distinguir la importancia de los personajes como, por ejemplo, cuando se describen los armamentos de Amauri (en dos versos, 1601 y 1606) y de Huon (mucho más extenso: 1594-1600 y 1626-1631) antes del combate.

Como sucede con las tiradas, alargar un motivo produce, paralelamente, la detención de la acción, que avanza con mayor lentitud. Aquí, la multiplicidad de aventuras y la importancia de la intriga en los textos imponen otras exigencias y, sumadas a las tendencias estéticas del autor, amplían las maneras de elaborar el relato a partir de modificaciones de motivos tradicionales mediante el entrecruzamiento de materias. Un ejemplo podría ser la diferencia que mencionamos en el armamento de Huon dado que, en lugar de equiparse en un bloque como se haría tradicionalmente, aquí, en cambio, se describen de manera separada dos momentos: uno antes de ver al rey y de realizar el juramento, y otro después. De acuerdo con el análisis de Rossi (1975, p. 166), esto le daría más verosimilitud al relato. Un segundo ejemplo podría ser la modificación sobre el motivo de la comida, explotado en el episodio final. En Huon, el motivo aparece fragmentado en tres partes (preparativos, desarrollo y conclusión) a las que se 
dedica un verso y se intercala con intervenciones de otro tipo. De este modo, el entrelazamiento de temas diferentes daría lugar a efectos narrativos más dramáticos: el festejo del banquete contrasta con el episodio yuxtapuesto del héroe en su prisión comiendo tristemente. En un segundo momento, se intercalan las palabras de Naimes criticando la dureza del corazón de Carlomagno. Vamos vislumbrando un tratamiento del motivo como materia maleable y polivalente con tonos y significados que pueden modificarse de acuerdo con el contexto.

Por otra parte, advertimos otras alteraciones que resultan más radicales porque afectan directamente al esquema narrativo. Detengámonos en las variantes que se perciben en el duelo judicial y en la emboscada. Por un lado, los juicios por duelo suelen terminar con la muerte del culpable, pero aquí se incorpora el valor agregado de demostración moral; confesión exigida como prueba que pierde su valor luego de la muerte de quien la pronuncia. En consecuencia, Huon sigue siendo considerado culpable y marcha al exilio. Por otro lado, en la emboscada, el combate es remplazado por dos duelos sucesivos que, narrativamente, provocan la muerte del hijo de Carlomagno.

A pesar de hacer hincapié en la épica, Rossi (1975, p. 170 y ss.) también considera que, a partir del ingreso de Auberon, en Huon el poeta comienza a trabajar con elementos que normalmente no aparecen en los cantares de gesta. Lo maravilloso no queda aislado ni encapsulado en el momento del ingreso al bosque ni en determinados objetos o personajes, sino que contamina las partes narrativas vinculadas con el 
cantar de gesta y la novela de aventuras. El motivo de hacer sonar el cuerno, que antes mencionábamos como intermotivación, aquí aparece como transposición de la Chanson de Roland. Más allá de la conceptualización teórica, en ambos casos queda claro que el cuerno funciona como emblema de la hibridación genérica y que, a su vez, mantiene la tensión entre dos géneros en disputa en la época de composición del texto (chanson de geste y roman). En Huon de Bordeaux la naturaleza y el rol de los motivos conllevan una forma de evitar extensiones narrativas. A su vez, en el tratamiento y el trabajo con los motivos el narrador demostraría poseer una conciencia clara de lo arbitrario y artificial de ciertas convenciones literarias, a partir de un conocimiento amplio de la técnica del cantar de gesta. Contrariamente, los motivos de tipo oratorio y descriptivo más relacionados con la performance juglaresca son poco preferidos.

Consideramos a los géneros literarios como parte y producto de los contextos culturales. En este sentido, creemos que el "género" es un concepto de por sí dinámico en tanto deviene de la interacción entre escritores, lectores, textos pasados y contextos (Devitt, 2000). Más aún cuando se trabaja con cruces, interferencias e hibridación. En esta línea, los géneros son definidos y redefinidos históricamente de acuerdo con propósitos, sujetos y funcionalidades específicas. En relación con el recorrido a través de la recepción de los textos (Lacalle, 2014b), resulta evidente que la utilización de Huon de Bordeaux y Le roman d'Auberon y, específicamente, del análisis de sus materias y géneros, varía de acuerdo con la visión y el objetivo de cada especialista. Como ejemplos paradigmáticos 
observamos distintas etapas. En primer lugar, el caso de Marguerite Rossi (1975, p. 15 et al.), que busca realzar el carácter épico "puro" del texto. En segundo lugar, Gaston Paris (1861, p. 353) que, inversamente, contrasta a Huon con el cantar de gesta paradigmático, Chanson de Roland, para rescatar las características maravillosas, relacionadas con la novela de aventuras y con el Kunst-Epos. En tercer lugar, en los estudios más actuales (Casanave, Berthelot) se pasa a considerar ya no la preeminencia de un género u otro, sino la hibridez genérica con una valoración positiva. Dicha valoración se sostiene en el acento sobre determinado tipo de motivos en pos de un objetivo político, ideológico y cultural específico. Durante el siglo XIX, la configuración de las distintas naciones europeas iba de la mano de una valoración especial de la épica. Promediando el siglo XX, la revalorización y centralidad de la novela en las producciones literarias y en los debates teóricos, con el roman como su antecedente medieval, posibilita otras lecturas. Por último, y a partir, sobre todo, de la década del ochenta, los enfoques transnacionales e interdiscursivos rescatan en sus análisis los textos de naturaleza híbrida, para los que tanto Huon de Bordeaux como Le roman d'Auberon son objetos sumamente productivos. 


\section{Referencias Bibliográficas}

Berthelot, A. (2003). "Les continuations de Huon de Bordeaux: chansons de geste ou romans?”. XVIe Congrès International de la Société Rencesvals, Granada.

Cazanave, C. (2008). "Morgue et Arthur dans la tradition des Huon de Bordeaux". Actas del XXII Congreso de la Sociedad Artúrica Internacional, Rennes. Recuperado de http://www.uhb.fr/alc/ias/actes/index.htm

Devitt, A. (2000). "Integrating Rhetorical and Literary Theories of Genre”. College English, 62 (6), 696-718.

Guerreau-Jalabert, A. (1992). Index des motifs narratifs dans les romans arthuriens français en vers (XIIe-XIIIe siècles). Ginebra: Droz.

Kibler, W. y Suard, F. (2003). Huon de Bordeaux. París: Honoré Champion Éditeur.

Lacalle, J. M. (2014a). "'Ciert tout fantomme quant que vous y vairez': aproximaciones al estudio de lo maravilloso en Huon de Bordeaux". Exlibris, 3 (3), 151-7.

Lacalle, J. M. (2014b). "Huon de Bordeaux en la filología decimonónica: la Eneida de Gaston Paris”. En El erudito frente al canon II. Por una filología de la historia literaria (pp. 197-210). Buenos Aires: Instituto de Filología y Literaturas Hispánicas “Dr. Amado Alonso”.

Lacy, N. (1996). "Motif transfer in Arthurian Romance". En The Medieval Opus (pp. 157-68). Amsterdam: Rodopi.

Paris, G. (1861). "Huon de Bordeaux". Revue germanique, 16, 350-90.

Rossi, M. (1975). Huon de Bordeaux et l'évolution du genre épique au XIII siècle. París: Honoré Champion Éditeur.

Subrenat, J. (1973). Le roman d'Auberon. París-Ginebra: Droz. 
Thompson, S. (1955-58). Motif Index of Folk Literature (tomos I-VI). Bloomington: Indiana University Press.

Fecha de recepción: 03/o8/2017

Fecha de aprobación: 27/11/2017 